\title{
Empirical Analysis of Implication of WTO on Rice Market
}

\author{
Dr.Imamuddin Khoso
}

Assistant Professor

IBA-University of Sindh, Jamshoro

Dr. Nanik Ram

Assistant Professor

Department of Economics, University of Sindh-Jamshoro

Ikhtiar Ahmed Ghumro

Assistant Professor

Department of Commerce, Shah Abdul Latif University Khairpur Mirs

Faiz.M.Shaikh

Assistant Professor

Department of Agri: Economics, SZABAC-DOKRI-SINDH-PAKISTAN

E-mail: faizshaikh@hotmail.com

Received: July 25, 2010

Accepted: September 13, 2010

doi:10.5539/ijef.v3n2p159

\begin{abstract}
This research investigates the impact of WTO on the World Rice markets and from last five years and their impact on the Pakistan's export earnings as well as in economy. Data were collected from the Primary as well secondary sources of the Rice producing countries The URAA imposed relatively few policy changes for rice; yet these changes are having observable effects .The URAA has caused Pakistan to makes significant adjustments to its international market effects are possible from this policy changes. The other major identifiable policy changes relate to the increase export to developed countries. Pakistan. Model projections of the effects of the URAA on rice suggest increase of $7 \%$ were to occur it will be a very long time before we would have enough data to reject the hypothesis of on changes in the world price of Rice . Faced with this data problems we turn to the specific market for high quality Pakistan Rice to look fore to look for market impact base on our review of the polices and market realties. It was revealed that from the last five years there is no visible impact on export laid growth but from last thee years price shocks was observed in Pakistan, due to increases in the world rice market by 200 percent in various Asian countries. Consumers are facing the price shock problem in Pakistan and world Rice market the statistical results were similar for the alternative specification of gross margins and prices as the economic decision available. However, the price elasticities derived using the gross margins specification were about a third of those using the prices specification. The gross margin specification yielded additional information in the form of yield and input cost elasticities.
\end{abstract}

Keywords: Supply, Response, Rice, Growers, Sindh

\section{Introduction}

The effects of an international trade agreement may be considered in three channels. First we may examine changes in the member country policies. This is the most straight for clear whether policy changes are attributable to the agreement .Second we may examine the impacts of these policy changes on market part to the paper we point out creation complications that that make such an assessment less straightforward Finally we acknowledge that and indirect effects on a market by effecting overall economic growth and even the confidence for investment in an industry, For example many have argued that the impacts of China's accession to the WTO will have broader and indirect implications for property that these impacts may dominate the specific commodity-by-commodity effects. In this paper we do not analyze the broad and indict influence of the creation of the WTO on rice markets but rather focus on more specific rice provision of the URAA. 
Agriculture is the largest sector of Pakistan's economy. The agriculture sector contributes around 24.1 percent in GDP, and engaged half of the total employed labor force. It is largest source of foreign exchange earnings and meets raw material needs' of country's major industries such as textile and sugar production. (Economic Survey of Pakistan (2007-08).The growth in the agriculture sector increased from 4.6 percent to 7.8 percent in the current year. This increase attributes to 9 percent expansion in major crops, 4.9 in minor crops, 5.6 percent in livestock, and 8.3 in fisheries sector. A feature of improved growth in the agriculture sector is record production of wheat and rice and recovery in cotton (Economic Survey of Pakistan 2007-08).Improved growth in a agriculture sector is attributed to the government's agricultural policy reforms such as waiving of interest on loans, introduction of Khushali bank, support price policy and introduction of micro credit facility. The growth is also attributed to timely measures to get cotton out of deep-seated crisis (et al S.M.Nasir)

Rice is the second principal food and commercial crop and occupies about $10 \%$ of the total cropped area. The total cropped under the rice during the year 200519 thousand hectares, and production was 2503, Hec, and Production 4991 tones. Thailand, India, Chad are the main competitors of Pakistan (et al Shaikh) the government of Pakistan is taking effective measures to increase the yield, production and quality of export rice. Research efforts are continuing on developing high yielding basmati and IRRI varieties. Emphases are also being laid on agronomic research as well as on improved extension services, fertilizer use, direct seedling etc. The flow of input and credits is also being substantially increased. Agriculture was a centerpiece of the Uruguay round of trade negotiations that created the World Trade Organization (WTO) and occluded in 1994 .Implications of the Uruguay Round Agriculture Agreement (URAA) began in 1995 and will continue to 2001 for developed country and to 2005 for going countries. This article reviews the evidence and asks what have been the effects of the URAA for rice?

Empirical projections of the Uruguay Round Agriculture Agreement have taken several forms. Several authors and organizations have developed computable general equilibrium or other multi-market models that were applied to cuts in tariff equivalents or other policy representations.(See for example the studies surveyed in Sharma, Konandreas and Greenfield) other have considered specific evaluation of the elimination or continuation of particular barriers or subside (Cramer, Hansen and Wailes,Dyck et al; at Song and Carter).This article first into the middle ground .We look specifically at rice and assess short term impacts the agreement for which implementation began in January 1995 just eighteen years back. Our analysis is explicitly partial equilibrium and relatively informal. This provides the flexibility to lay out what we believe is the most important results. We then test our under standing with a look at the recto history, off course ,the biggest problem with and empirical assessment is that five years provides relatively little data and this period has implementation of the URAA .In the period since the beginning of the implicational of the URAA we have also experienced:

- A new 1996 U.S far, act,

- Major EI Nifco and La Naïf climate events.

- The Asian financial crisis and related to the above

- A collapse in Amy commodity price and finally,

- Unprecedented direct payment Soto farmers in the Pakistan

Given this background our questions are ahs the WTO agreement had any discernable impacts on rice supply demand or price and if so what have those impacts been? Many papers, such as those cited above and in Sumner and Tangremann,have provided simulaaricle is instead toe consider some very specific agreement as it ahs been implemented against the background of other policy and market events.

\section{The World Rice Market}

Two stylized facts are always listed in characterizing the world rice market. First the market is thin in the sense that the rational exporters to production are smaller than for other grains. Second the market is segmented by type and quality .Both of these characterizations should be examined more thoroughly but we have the space here for only a couple of comments on each.

About 23 million tones of rice ( $5 \%$ or $6 \%$ border traded each year ). This small ratio of trade is the typical indication for thinness of the international rice market (compared to other grains ) and thinness is often attributed to traded barriers(USDA 1999a).The major implication of thinness is that rice price are volatile in world markets . The link from a thin markets price variability is not simple but roughly speaking can be thoughts of as large potential shifts amount typically in the market. In this context we not that rice is the staple food for the there largest developing nation -China India and Indonesia given the size of these countries it is not suprisingtaht most rice production does not cross international border. If China Indonesia, Pakistan and India were fragmented politically as Europe we would see much more international rich trade just as when we treat the ever larger European Union as a single country other international markets begin to look thinner 
Also because the largest producers and consumers of rice are developed as well underdeveloped countries a high production of world rice production never levers the farm on which it is production. This rice is often quite insulted from world markets by transaction cost per hact/ a third is consumed on the frame where it is produces and another hired is consumed in newly rural or urban population centers with the large nation where it is produced .This suggest that trade barriers are only one sources and perhaps not them cost impotent sources of the rice market thinness.

The second fact is that the rice market is segmented .There is indeed is the the rice notes whether rice production and consumption in a country is mainly japonica or indicia Rice industry analysis often segment the market much father by quality and degree of processing prior to export (Wailes,USAD 1999. Childs and Hoffman).This segmentation is not prefect. In many markets there is considerable substitution between japonica and indicia rice and for some processing used such as beer or production of rice flour the preceptor broken grain matter lamentation but also note that relatively littler formal analysis of this question has been conducted. We note that of the 23 million tones of rice traded internationally about $85 \%$ our less than half is high quality japonica rice are produced and consumed each year only about 1.5 million tones of high quality japonica rice is traded.

\section{A Review of the URAA for Rice}

Before considering effects to the URAA for the rice markets just described let us provide some background on what the URAA actually did for rice .The major parts of the GAT./WTO Uruguay Round Agreement for Agriculture are by now well known. We will review the features only briefly in the context of rice trade and focus on where the agreement actually had effects policy changes (See jostling Triggerman and Wryly for a review of the GATT the WTO and the URAA Sumner and Trangermannn for a review of the agricultural economics literatures surrounding the URAA and yap orWailesformore detail on drive provisions). The export subside provisions the URAA for rice were only or were only or potential singificecance of the EU and the Pakistan(Yap) Moreover the US export Enhancement program (EEP) has not been used for rice since 1995 . This had little or nothing to do with the URAA limits but rather recognition that the program has not been effective when it was used .The EU continue to use export subsides but and the states and the EU use food aid programs to ship rice to poor countries these programs have not been affected by the URAA U.S planed by the URAA we conclude with other authored the export provisions for the rice are not or the further discussion.

The internal support precisions of the URAA include $24 \%$ reduction in the aggregate measure of Support (AMS) over six years $(13.3 \%$ over ten years for developing countries and detailed rules about how programs qualify for exemptions and exceptions the reductions are from a base with very high subsides and apply to an aggregate disciplined rice specifically. Very few policy or market changes for commodity can be attributes to the internal support provisions of the URAA (Summer and Hagerman Childs and Hoffman ) Pakistan rice policy is an exception. To better understand the application of the URAA internal support precisions we will compare the program adjustments for rice in the Pakistan.

Pakistan does not export rice and took advantage for the special URAA Annex 5 precision to establish an ambulate quota rather than a tariff rate quota for the rice Cramer Hansen and Willies Chor and Sumner) Therefore whatever their the effects internal support policy changes for rice imposed by the URAA have had and could have had no impact on international trade .this changes for rice in Pakistan that were imposed by the international trade agreement requirements obviously could not have had any effect on internal trade Nonetheless and this aspect had been among the most significant impact of the URAA on rice. Pakistan agricultures dominated by rice which traditionally covered the majority of the cropland and farm value of production.

The major part of the Pakistan Rice program long was and remains government procurement of a portion of national rice production. Which year the congress is a government purchase price and a quantity of Rice to be purchased by the government price Pg was about $25 \%$ above the market price for which commercial rice sells in Korea Pm .The internal market price is about four times the border price. The right to sale to the government is allocated to provinces countries villages and finally to individual farmers through a kind of quota system .before 1995 , the amount of rice covered by the government purchase typically accounted for about $25 \% \mathrm{f}$ the total crop .It is not set as a share, but rather as a quantity detained each year and allocated roughly but not strictly in proportion to the historically production of each region each villagers and each farm within a region. The government uses the rice it buys military and other government requirements or sells the rice back into the market at prevailing market price. The contribution of this policy to as the amount of the government purchases Q gt time the difference between the government punchers price $\mathrm{P}$ gt and the international reference price $\operatorname{Pr}$. This component of the AMS may be decomposed as'

$$
\begin{gathered}
\text { AMS support }=\text { Qgt }(\text { Pit }- \text { Pmt }) \\
+ \text { Qgt }(\text { Pmt }- \text { Pr })
\end{gathered}
$$


and the bulk of the AMS is comprised of the second term which depends on the import quota not the internal support policy. Thus this calculation of internal support really has little to do with a Pakistan internal support policy and everything to do the border measure. The second point to notice is that because $\mathrm{Q} g$ is set in advance as a quantity eligible for a high price and because $\mathrm{Qg}$ is far smaller than total out put $\mathrm{Q}$ it follows that $\mathrm{d} \mathrm{Q} / \mathrm{dQg} \approx 0$ and $\mathrm{dQ} / \mathrm{dPg} \approx 0$. This means that the supply effects of the Korean internal support policy are closet zero figure 1 illustrates this point by showing that the internal supply and demand situation is essentially unaffected by the government purchase program is like an infra-marginal payment ( Pg-Pm)Qg accounting for about $4 \%$ of market revenue Pm Q Pr ) Qg is four times as larger to about $16 \%$ of market revenue even when calculated to include the impact of the import quota the rice AMS is relatively small compared to rice market revenue in Korea whereas the import quota account for a tariff equivalent of about $400 \%$ In response to the URAA Korea has cut both Pg and Qg But of course whenever Qg is above zero the AMS trains large Baucus the domestic market Price Pm remains much larger than the world references price Pt .

The Rice policy situation in the Pakistan stand in sharp contrast the situation in India and other south Asian countries Rice account for only about $9 \%$ of total agricultural value so the amount of internal support for rice has only great effect on the overall AMS commitment .Prior to 1996 Pakistan required some rice land to be idled in return for direct payments that were tied to rice base arrangements that were tied to rice base acreage historical yield and currant market price After 1990 these deficiency payments were calculated on only a peritonea farmers rice base and were relatively unconnected to current year production After 1996 the link to current production was father weakened and these called contract payment was also fixed independent of market prices However since 1985 rice farmers have been eligible for a payment on all current production that's calculated as the difference between a government calculated world price .The contract payments have been declared exempt from the AMS whereas the second set of payments the marketing loan benefits fall directly within production enhancing internal support and are this included in the AMS

In 1998 because farm prices of most commodities were unusually low, in Pakistan increased the contract payments by 50\% In 1999 with price remaining low the contract payments were doubled .Thus Us commodity subside including additional crop insurance subside have expanded greatly .A big jumps rice payments the doublings of contract payments and substantial farm subside and no adjustment in rice programs is contemplated in reposed WTO commitments.

The import access commitments of the URAA included both tariff reduction and expanded quantitative access. For rice, tariffs are being cut by most developed countries by $36 \%$ over six years and by most developed countries by $24 \%$ over ten years. As for other farm products cuts of only $15 \%$ are being applied in some developed countries and cuts of $10 \%$ are being applied in some developing countries. Further these rules apply to bound rates and for some (developing) countries the import duties actually applied are well below the bound rates already .Yap provides a useful and accessible summary of these

Insert Figure 1 Here

Commitments for rice (see also Wailes). The bottom line is that small tariff reductions spread across many countries are likely to have allowed more import access in many markets .including Europe and Latin America, and south East Asia. A number of countries also provided commitments for improved quantitative access. Among these, commitments by Thailand the Philippines and Indonesia my look significant on paper by in fact could no have had significant effects on rice markets in the five years since implementation. Thailand is the major low cost rice exporter. Thus although the border is now more open no significant quantity of new imports entered .Conversely far more rice in the past five years than their minimum access requirement and their commitments turned out to be redundant.

A second significant aspect of Japan's import regime is that even through it is not destined for the domestic table rice market most of the imported rice has been of the japonica type and most has been of relatively high quality .As indicated by the uses of the rice in Japan there has been no real commercial reason for this choice to pay the extra cost for rice of relatively high quality (Duck et al). Under the close scrutiny of exporting industries and government especially in Australia and the Untied States the Japan food Agency has chosen to distribute is the combative advantage to supply rice to the commercial outcome. Such an outcome may not be coincidental as might first appear.We recognize that political effects depend on overall political and economic relationship as well as on the effort expended on a particular commodity but the political pressure to open a market also follows the economic benefits anticipated.

Pakistan has handled rice access differently .Although they are now an OECD member for the URAA Korea declared itself developing country. They also took advantage of the special precision in the access agreement of mutation an absolute import quota for rice that grows from about 0.057 million tone (about $1 \%$ of domestic consumption is the base period ) to about 0.21 million tone by 2004.Korea also uses state trading and does not let 
the imported rice compete directly in the domestic market .But rather than mimicking an approximate market out come with a political instrument as is done in Japan ,Korea buys rice from the lowest-price bidder in an open tender system. The result is that Korea has not bought japonica rice from the United State or Australia but rather has purchased low quality rice from China and India (Choy and Sumner) A commercial outcome would select a quality of rice to maxmi8ze the difference between the Korean is forgoing substantial quota rents that could in fact be redistributed to rice farmers. Now let us turn to measuring market impacts of these policy changes.

\section{The Potential to Observe Market Changes in Only Five Years}

The biggest problem with assessing the effects of the URAA or any other market change is to distinguish consequences of that event from the background variation in the data To consider the nature of this problem more carefully we must compare the magnitudes of projected price increases from models of the implication of the URAA to the amount of background rice price verbally. Projected increases for the price of rice rang from about zero to $7 \%$ (Sumner and Tangermann Sharma, Konandreas and Greenfield). The simples' assessment approach is a statistical test on whether the mean price of rice is different in the per-URAA and post URAA periods. Our data question then becomes if the increase in mean price form the URAA really was 7\% how many years would we have to wail to find a "significant" effect in the post URAA data? Consider solving for post URAA simple size Tnew, such that we reject the hypothesis Pnew -Pold $=0$ where Pnew is the estimate of mean price after the URAA and Pold is the estimate of the meaning a per-URAA sample of size $\mathrm{T}$ old .For simplicity lets assume that the distribution did enough such that we have a sample large enough such that we may replace the variance by their sample estimates and that the annual observation are independent over time. With these simplification all of which reduce the required sample size the expression for the test statistic is

$$
\frac{(\text { P new }-\mathrm{P} \text { old })}{\left[\left(\mathrm{o}^{2} \text { new } / \mathrm{T} \text { new }\right)+\left(\mathrm{o}^{2} \text { old } / \mathrm{T} \text { old }\right)^{1 / 2}\right.} \geq 1.65
$$

where we have used 1.65 to represent a $5 \%$ significance level for a one tailed test (Hole).If the left side is larger that 1.65 we reject the hypothesis of equal means in favor of the hypothesis that the man price is larger in the post -URAA period .To proceed, we (a) assume explicitly that $\sigma^{2}$ new $=\sigma^{2}$ old (b) use the fact that the new price is assumed to be 7\% above the old price (c) apply the fact (assumed known with certainty) that there is about 0.2 and (d) apply the fact that the per-URAA sample size is about twenty years. With these estimates and assumptions we find that there is no sample Tnew large enough such that we could reject the hypothesis of equal means and the background variability in price. No matter ho0w precisely we were able to admeasure P new the uncertainly $7 \%$ price increase if we had a sample of thirty years of per-URAA Data the required post URAA sample would be eighty six years $\mathrm{N}$ o wonder looking for "Significant" market wide confirmation of model projections is frustrating! (Will Marin's comments below provide a clear explanation for why our simple illustration may be too pessimistic?)

We should be clear about the implication of these calculations. The URAA may have already had effects on markets and market prices but it will take more data than will be available anytime soon to show convincingly these effects in aggregate price series or test the straightforward aggregate

Hypotheses that come from the various projection modeless. The hypothesized impacts are simply too results will help explain who economic can continue to argue at opening trade is having important impacts while it is so difficulty to get data to show the impacts.

\section{Effects of the URAA for High -Quality Pakistani Rice Price}

The analysis of policy sifts caused by the URAA suggests that impacts should have been fetes first in the market for high quality Pakistani Basmati rice .by 1999 additional imports into Japan and Canada amounted to about 0.7 million tone or about $3 \%$ of world trade. About half of this total has been high -quality Basmati rice imported by Japan from California and Australia .This amount accounts for about $25 \%$ of trade in high quality Basmati Rice based on these facts we look or the effects o the URAA in the price of high quality Pakistani rice .In a simple liner in loges model $\mathrm{d}$ in price In (Price ) $=(\%$ demand shift $) /(€-\eta)$, Where $€$ is the relevant excess export market and $\eta$ is the relevant excess demand in this world market. Treating the new import into japans as a $25 \%$ demand. Shift and with elasticity's that are not too lager we hypothesize observable price effects may emerge. Another way of putting the point is that the price effect in the high quality Pakistani Basmati Variety of Rice has relative market to the baseline India rice price should be lager enough to overcome the sample size curse calculated above.

Our empirical approach is highlighted by figure 2. which shows the ration of the analysis detailed above we hypothesize that the URAA has increased the price of California export rice $(\mathrm{P}$ cal) relative to the international price of indicia rice represented by the. Thai other market and economic factors affecting the rice market and so we have 
included a few of those in a linear regression to test our hypothesis. We use data for 1981/82 through 2006-08 to estimate the following equation.

$$
\begin{array}{ll}
\mathrm{P} \text { cal } & =\mathrm{a}+\mathrm{b} 1 \text { ( Japan import) } \\
\hline \mathrm{P} \text { thai } & \\
& +\mathrm{b} 2 \text { (Cal yield ) } \\
& +\mathrm{b} 3 \text { (Price soy) }+\mathrm{e}
\end{array}
$$

where Japan import is the quantity of Japanese annual impost (in hundred weigh per acre) reprinting supply shocks and price soul is the price of soybeans (in $\$$ per bushel) representing the general movement of commodity price and the price of an alternative crop in Pakistan rice growing regions. We expect $b 1$ to be positive and significant to reflect the impact of the URAA .Results are.

\begin{tabular}{ll}
$P$ cal & $=2.88$ \\
\hline P Thai & $(0.59)$ \\
& +0.111 (Japan import) \\
& $(0.066)$ \\
& -0.0056 (Cal yield) \\
& $(0.068)$ \\
& $-0.17 \quad$ (Price soy) \\
& $(0.040)$
\end{tabular}

Where the Durbin - Watson $=16$, the $\mathrm{R} 2=0.59$ and where stander errors are shown in parentheses.

The show that when we represent the URAA by a demand shift that reflects Japan's import of rice we identify a positive effect on the relative price of japonica rice at the $6 \%$ level Of statistical significance for an one tailed test An increase in Japan imports by 0.5 million tones increased the price ratio by 0.055 . That is holding the Thai price fixed at $\$ 300$ million tones of additional imports would raise the price of Pakistani Basmati rice by $\$ 16.50$ per tone. Results with the same signs and orders of magnitude were obtained looking at the ration of Pakistani Rice Market.

\section{Conclusions}

This brief article makes several points The URAA imposed relatively few policy changes for rice; yet these changes are having observable effects. The URAA has caused South Koran to makes significant adjustments to its international market effects are possible from this policy changes. The other major identifiable policy changes relate to the increase in import of rice by Japan and Canada. Model projections oft he effects of the URAA on rice suggest increase of $7 \%$ were to occur it will be a very long time before we would have enough data to reject the hypothesis of on changes in the world price of rice. Faced with this data problem we turn to the specific market for high quality Pakistani Basmati rice to look for high quality for market impact. Based on our review of the polices and market realties, we expect that the ration of the japonica to indicia rice price has responded possibly to the increases in the quantity of Japans ride imports that are driven by the URAA. We test this hypothesis and find that the relative price of Pakistani rice has risen significantly in response to additional imports by Japan. Economists who project the market effects of the WTO and other trade liberalization efforts sometime have a credibility problem. Our projection molds seem to differences in policy specification or parameters. Even when a consensuses result can be obtained however it is difficult to confirm the results of the molds. Policy model projection are not forecasts and the baseline often changes. After showing some of the problems facing empirical assessments we examined a particle and very specific hypothesis to find market effects attributable to the rice policy changes imposed by the URAA.

\section{References}

Askari, H, and Cummings, J. (1977). Estimating agricultural supply response in the Nerlove model, a survey. American journal of Agricultural Economics, Review,18,page.257,292.

Choi, J., S. Min, D. A. Dornfeld, A. Mahboob, T. Tzong. (2000). Modeling of Inter-Layer Gap ... T. Swartz and D. Iacobucci, London: Sage Publications (2000). Janet Bercovitz), 6 Journal of Industrial Ecology (Summer-Fall 2002), 103-124.

Cochran, Donald A, b. 12-5-1915, d. 6-13-1995, US Navy WW II Cochran, James Majoric, b. 1903, d. 1977, PFC US Army, WW II Cooke, Shane C, b.

Economic Survey of Pakistan. (2005-06). Ministry of finance, Government of Pakistan 
Jaforullah, M. (1993). Asymmetric supply response: evidence from Bangladesh. Journal of Agricultural. Economics, 44, 490, 495

Lim, S.L. (1999). The supply response of primary producers, Penerbit University Malaysia. Maitha, J.K. (1970). Productivity response to price, A case study

Maitha, J.K. (1970). Productivity response to price, A case study of Kenyan. Coffee East African Economic. Review, 23-37. Ogbu, O.M. Gwetibou, M., (1990).

Nerlove, M. (1958). The. dynamics of supply (The Johns Hopkins Press, Baltimore). Nerlove, M. and K.F. AVallis,1966, Use of DurbinWatson statistic in.linkinghub.elsevier.com/retrieve/pii/0014292174900233.

Ogbu, O.M. Gwetibou, M., (1990). Agricultural supply response in sub-Saharan a critical review of the literature. Afr.Dev.Rev, 2, 83-99.

Sumner AD and S Tangermann. (2002). International Trade Policy and Negotiations: H handbook of Agricultural Economics B B.Gardner and G Rausser eds Amsterdam Nother Holland Forthcoming 2000. Amer J. Agri. (November 1996) Economic, 788891-905.

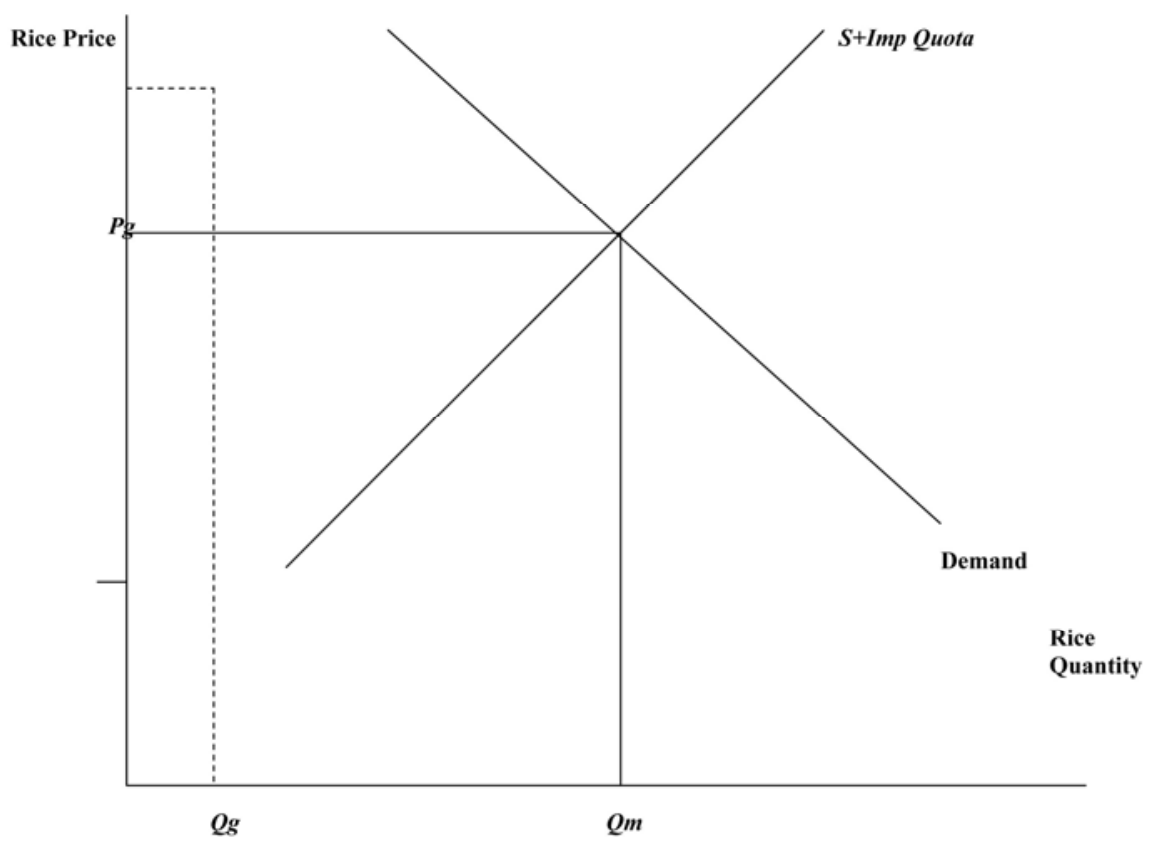

Figure 1. Pakistan Domestic Support Policy for Rice 